\title{
APRENDER E \\ ENSINAR SOB \\ A ÓTICA DA \\ TEORIA DA \\ MODIFICABILIDADE COGNITIVA \\ ESTRUTURAL DE \\ FEUERSTEIN E \\ DA PEDAGOGIA \\ FREIREANA
}

LEARNING AND TEACHING FROM THE PERSPECTIVE OF FEUERSTEIN'S

THEORY OF STRUCTURAL COGNITIVE MODIFIABILITY AND FREIRE'S

PEDAGOGY

APRENDER Y ENSEÑAR DESDE EL PUNTO DE VISTA DE LA TEORÍA DE LA MODIFICABILIDAD COGNITIVA ESTRUCTURAL DE FEUERSTEIN Y DE LA PEDAGOGÍA FREIREANA

Arnaldo Nogaro

Roque Strieder ${ }^{2}$

Rute Rosângela Dalmina 
'Doutor em Educação pela UFRGS. Docente do Programa de Pós-Graduação em Educação Universidade do Alto Vale do Uruguai (URI) - Frederico Westphalen - RS Brasil.

2Doutor em Educação pela PUC/SP. Docente do Programa de Pós-Graduação em Educação da Universidade do Oeste de Santa Catarina (UNOESC) - Joaçaba - SC Brasil.

${ }^{3}$ Mestranda em Educação pela Universidade do Alto Vale do Uruguai (URI) - Frederico Westphalen - RS - Brasil.

Resumo: A teoria da modificabilidade cognitiva estrutural se fundamenta na crença de que todo ser humano é capaz de aprender desde que esteja aberto às mudanças, independentedesuaidade, condiçãogenéticaouexperiência de vida. Partindo dessa premissa, este artigo, fruto de pesquisa teórica, aborda possibilidades de a mudança cognitiva estrutural dar-se de forma similar ao que ocorre nas mudanças naturais e contínuas dos aspectos biológicos cronológicos de uma pessoa, sendo que a diferença entre ambas estaria no fato da primeira ser opcional; e a segunda, determinada. A partir desta predisposição do sujeito, surgem novas formas de aprender e ensinar que podem ser incorporadas ao exercício cotidiano da prática docente para que este possa contribuir com sua modificabilidade cognitiva. Para corroborar com essa perspectiva, buscaramse nos princípios pedagógicos da pedagogia freireana bases teóricas que fundamentam os saberes necessários à adoção desta prática. A modificabilidade cognitiva ocorre quando são criadas as condições adequadas, sejam elas da parte do professor ou do estudante, para isso se exige a superação da pedagogia conservadora que impede a autonomia, o diálogo e a criticidade, princípios basilares da pedagogia de Freire e considerados elementos essenciais para gerar a modificabilidade cognitiva estrutural. 
Palavras-chave: Modificabilidade; Formação Docente; Prática Pedagógica; Ação e Reflexão.

Abstract: The theory of structural cognitive modifiability is based on the belief that every human being is able to learn, provided they are open to change, regardless of age, genetic condition or life experience. Based on this premise, this article, which is the result of theoretical research, discusses the idea that structural cognitive change is similar to the natural biological and continual changes that occur in a person, over time. The difference between them lies in the fact that the first is optional, while the second is predetermined. Based on this predisposition of the subject, new forms of teaching and learning emerge that can be incorporated into the daily teaching practice, so that they can contribute to the student's cognitive modifiability. To corroborate this perspective, we looked to the pedagogical principles of Freire's, for the theoretical bases underlying the knowledge necessary for the adoption of this practice. Cognitive modifiability occurs when the right conditions are created, whether by the teacher or student. For this, it is necessary to overcome the conservative pedagogy, which prevents autonomy, dialogue and criticism, all of which are basic principles of Freire's pedagogy, and are considered essential elements for generating structural cognitive modifiability.

Keywords: Modifiability; Teacher Training; Pedagogical Practice; Action and reflection

Resumen: La teoría de la modificabilidad cognitiva estructural se fundamenta en la creencia de que todo ser humano es capaz de aprender cuando está abierto a los 
cambios, independientemente de edad, condición genética o experiencia devida. Partiendo de esa premisa, este artículo, fruto de investigación teórica, aborda posibilidades de que el cambio cognitivo estructural pueda darse de forma similar a lo que ocurre en los cambios naturales y continuos de los aspectos biológicos cronológicos de una persona, estando la diferencia en el hecho de que la primera es opcional y la segunda determinada. A partir de esta predisposición del sujeto surgen nuevas formas de aprender y enseñar que pueden ser incorporadas al ejercicio cotidiano de la práctica docente para contribuir con su modificabilidad cognitiva. Para corroborar esa perspectiva, buscamos en los principios pedagógicos de la pedagogía freireana bases teóricas que fundamenten los saberes necesarios a la adopción de esta práctica. La modificabilidad cognitiva ocurre cuando son creadas condiciones adecuadas, ya sea por parte del profesor o del estudiante, y para ello se exige la superación de la pedagogía conservadora que impide la autonomía, el diálogo y la criticidad, principios basilares de la pedagogía de Freire y considerados elementos esenciales para generar la modificabilidad cognitiva estructural.

Palabras clave: Modificabilidad; Formación Docente; Práctica Pedagógica; Acción y Reflexión.

\section{INTRODUÇÃO}

A s relações entre formação e trabalho passaram nos últimos 20 anos por aceleradas mudanças que atingem as atividades econômicas, sociais, culturais e políticas até os dias atuais. O reflexo dá-se direto no mundo do trabalho e no contexto educacional. Educar na sociedade da informação representa o que Lévy (2000) afirma ser o atual momento, a representação de uma revolução contemporânea das comunicações que teve origem com o aparecimento do ser humano na face da terra. 
No cenário contemporâneo a sociedade é marcada por uma instabilidade de valores e saberes. Conhecimentos desaparecem, transformam-se e se renovam, desafiando a capacidade do indivíduo de se adaptar e inovar para garantir seu espaço como ser humano, sujeito social e trabalhador. Freire (2007) escreve que uma educação preocupada com a formação do trabalhador perpassa a formação para um posto de trabalho, mas propõe formação consciente e crítica, de caráter político, com o intuito de promover novos modos de estar no mundo, de pensar, de sentir e de agir.

No ideário político, representado pelos segmentos governamentais, algumas iniciativas têm demonstrado estabelecer as bases nas quais devem ser pensadas políticas de educação para dar conta da formação para novos espaços e postos de trabalho. No documento apresentado pela Cepal/ Unesco (1992), fica notória a combinação entre produção e acumulação de conhecimento como sendo força que impulsiona e promove o desenvolvimento, gerando uma nova economia da educação. A partir dessa economia se reconfigura uma nova teoria para o capital humano, cujo termo "educação" está associado à instrução e à treinamento, para gerar mais capacidade de produção, e o desenvolvimento de competências focadas ao saber fazer, o que se considera ser uma parte do trabalho da escola. A outra está relacionada ao mundo da vida e do seu sentido, o que demanda uma educação que esteja voltada para aprender a ser.

Contrapondo o modelo de educação voltada para a aplicação de teorias que orientam a "ensinar a fazer", que não trabalham a compreensão, e o entendimento mais profundo em níveis cognitivos mais avançados, "[...] a teoria da modificabilidade cognitiva estrutural apresenta a modificabilidade como uma mudança estrutural que se processa na mente de uma pessoa" (FEUERSTEIN, 2013, p. 241), consequentemente mais propícia a ser duradoura e incorporada à dinâmica da vida pessoal. Pode-se constatar, por meio de alguns conceitos de inteligência vigentes entre os anos de 1940 a 1950, que consideravam a inteligência inata e mensurável através de testes padronizados, descartando-se qualquer tipo de teoria ou crença que sustentasse a inteligência como dinâmica, modificável e construída a partir de múltiplos fatores que podem ser trabalhados e desenvolvidos no nível cognitivo.

A partir dessa visão, Feuerstein qualificou a modificabilidade como cognitiva, considerando aspectos cognitivos, emocionais e motivacionais do 
comportamento humano. A modificação de uma parte implica a mudança do todo, é uma relação dinâmica, que age e interage com a pessoa no seu ambiente sociocultural. É uma relação que nunca é neutra, e sim caracterizada por vários elementos interconectados que se afetam mutuamente (FEUERSTEIN, R., FEUERSTEIN, R.S. FALIK, L.H., 2014).

A partir deste contexto, descrito por Feuerstein, pretende-se trabalhar o conceito da teoria descrita pelo próprio autor, em que a Modificabilidade Cognitiva Estrutural é o conceito central de um esquema teórico cujo propósito é explicar as diferenças individuais no desenvolvimento cognitivo. Apoiando-se no pressuposto de que a educação promove o desenvolvimento do indivíduo, por meio do meio físico e cultural em que está inserido, e que tem efeitos diferenciadores na constituição física emocional e intelectual de cada um, aportar-se-á nas ideias de Freire para fundamentar nossa crença em uma prática pedagógica que, guiada pela problematização, pelo diálogo, pela crítica, pelo olhar aguçado da esperança, possa contribuir com a mudança necessária na inteligência do sujeito, possibilitando-Ihe novos aprendizados, compreensões do mundo e construções de sentido (FEUERSTEIN, R., FEUERSTEIN, R.S. FALIK, L.H., 2014).

\section{REFLEXÕES ACERCA DAS MUDANÇAS NO ENSINAR E NO APRENDER}

Historicamente falando, a partir das décadas de 1980 e 1990, ampliaram-se os debates acadêmicos sobre as implicações da emergência da formação de um novo trabalhador, incorporando-se ao discurso uma postura de flexibilidade, de proatividade e de autonomia. Em tempos de mudanças, se o sistema educacional não reagisse, demonstraria fragilidade, morosidade e omissão. Foi um alerta para reformular o currículo, repensar a função social da escola e contemplar novas competências e habilidades comportamentais que poderiam ser desenvolvidas durante a formação.

Até a década de 1990, o termo Formação de Profissionais da Educação não era usual para identificar a formação dos agentes que atuavam na educação escolar. $O$ termo "formação de professores", em cursos de licenciatura, constava nos diplomas e nos projetos políticos pedagógicos das instituições, mas estava pouco disseminado 
entre os professores e estudiosos. A partir da Lei de Diretrizes e Bases da Educação Nacional de 1996, a expressão foi difundida, prova disto é que se dedicou o artigo 62, Título V - com a denominação "Formação de Professores", ao tema.

A expressão "formação" conduz a discussão para o sujeito da educação, personifica o que antes era impessoal - "educação", expressão genérica e abrangente que abriga inúmeras possibilidades. Freire (2007) destaca que não é possível fazer uma reflexão sobre o que é a educação sem refletir sobre o próprio ser humano. Formação pressupõe educar. Na sua visão, a formação é entendida como uma ação mais profunda e integral da pessoa, levando em consideração todos os saberes (do saber ser ao saber fazer). A formação é permanente, é uma extensão da vida porque compreende necessidades sociais e pessoais. Se o ser humano é um ser que vai fazendo-se, construindo-se ao longo de sua existência, de suas escolhas, a educação torna possível o esclarecimento sobre as mesmas e elucida suas possibilidades. Daí a importância de vivenciar processos educativos, sejam eles formais ou informais, que abram as avenidas fundamentais da humanização e da contínua aprendizagem. Aprender e viver possuem a mesma gênese e identidade, estão no mesmo cenário, pois o viver pressupõe o aprender para não perecer e o aprender devolve ao viver a beleza de novas descobertas e descortina suas inúmeras possibilidades. Neste contexto, o professor situa-se como aquele que participa da experiência do viver e do aprender simultaneamente. Como não se nasce professor, torna-se professor. A consciência desta tarefa é um processo adquirido durante a formação, seja por meio da aquisição epistemológica, seja pelas experiências de humanização.

Ainda na visão do autor citado, ensinar exige reflexão crítica sobre a prática, o exercício da docência envolve movimento dialético entre o fazer e o pensar, o pensar sobre o fazer. Um modelo pedagógico condizente com o fazer docente pauta-se na valorização das experiências pessoais dos professores, nas vivências e na superação da dicotomia de que curiosidade ingênua não pode se tornar curiosidade epistemológica.

É preciso, por outro lado, admitir que a formação carrega a responsabilidade de propiciar o desenvolvimento técnico-científico, pedagógico e humano, balizado por uma postura ética nas relações humanas. Por esse motivo ela não poderá acontecer de forma isolada, sendo olhada apenas por olhar externo, periférico, sem levar em consideração a estreita aproximação entre o sujeito e o meio. A 
formação permanente ganha significado quando é reelaborada pelo seu autor e assumida como indispensável para o crescimento e desenvolvimento humano.

A ação educacional de Freire (2007) - que viveu e lutou por questões essenciais de maneira simples - estava ancorada na educação do humano, a qual deve nascer da interrelação de homens e mulheres com a reiterada ideia de que ninguém liberta ninguém, ninguém se liberta sozinho: os seres humanos se libertam em comunhão. Seu objetivo é que os indivíduos tenham consciência do seu papel, das relações que existem entre o eu e o outro, do viver e do produzir, das mudanças que surgem a partir da intervenção no mundo.

Ao se considerar este processo de constituição dos sujeitos, reconhecidos como seres humanos, com identidade, com amor-próprio e em contínuo construir-se como cidadãos, legitimam-se novas posturas diante do educando, e assume-se e atribui-se outro sentido às relações entre educador e educando; adotam-se novas posturas, admitindo que novos saberes e experiências são o esteio para novas buscas, e um possível encontro de saberes.

O propósito inicial de criar novas formas de aprender e ensinar, a partir da teoria da modificabilidade cognitiva estrutural, traz Freire (2007) ao cenário de Feuerstein (2013), cujo processo de aprendizagem humana envolve diálogo, intenção e amor. Para ambos esses itens têm o mesmo peso e valor e são um processo que não acontece isolado. Ele se alimenta e sobrevive em uma pedagogia fundada na reciprocidade, na ética da alteridade, no respeito à dignidade e na própria autonomia do educando.

A Teoria da Modificabilidade Cognitiva Estrutural fundamenta-se na crença de que todo o ser humano é capaz de aprender desde que esteja aberto às mudanças, independente de sua idade, condição genética ou experiência de vida. Nessa perspectiva, torna-se possível a mudança de pensamento que leva a mudar atitudes, comportamentos e posturas diante da vida. A partir da incorporação de novos hábitos e redirecionamento para novos olhares, o professor colocase numa condição de aprendente, reflexivo e autônomo, assumindo o seu fazer pedagógico como um ato político. Na prática pedagógica ele age embebecido destes princípios e os dissemina por meio de sua ação no coletivo da sala de aula, criando condições, instigando e despertando nos estudantes a condição de ser "aprendente" e "ensinante" a partir da mudança de sua condição em função das experiências vivenciadas no contato também com o mestre em sala de aula. 
Perante as dificuldades do exercício da docência, Feuerstein (FEUERSTEIN, R., FEUERSTEIN, R.S. FALIK, L.H., 2014) aponta a necessidade de o professor conscientizar-se de que ele próprio é modificável e de que a capacidade de mudança do cérebro é definida como uma opção, ou seja, é sua decisão querer mudar ou não. Conforme destaca o autor, aceitar a mudança é um atributo indispensável à transformação do comportamento e das relações que permeiam o processo ensino-aprendizagem, é um componente essencial rumo à superação das dificuldades.

Na visão dos autores Feuerstein (2013) e Freire (2007), a pedagogia da autonomia oferece uma aprendizagem fundida em saberes relacionados ao humano, às relações, às trocas e ao respeito pela diversidade. É uma prática necessária ao fazer docente, pois requer não somente o saber fazer, mas, acima de tudo, uma forma de ser e de agir, com valores éticos e morais. A identificação do professor com a aprendizagem da pedagogia da autonomia exigirá mudanças profundas na sua prática, e mudanças direcionadas à sua prática educacional escolar de todos os níveis em que se pressupõe um novo modelo de escola. A aceitação desta necessidade passa pela ressignificação do papel da escola; professores e comunidade escolar trabalhando juntos, em razão dessas conquistas. Em decorrência disso, as mudanças educacionais serão estendidas para outros contextos sociais, possibilitando novas formas de ação social e desempenho de papéis sociais dos egressos da escola. A escola, sabendo disso, deve precaver-se para o perigo das ideologias e da reprodução social.

Freire (2007) previu na pedagogia da autonomia um critério de aprendizagem docente, que denominou de: ensinar exige reconhecer que a educação é ideológica. O autor usou uma analogia comparando a miopia a uma manhã orvalhada, na qual mal se vê o perfil do cipreste. "A própria miopia que nos acomete dificulta a percepção mais clara, mais nítida da sombra. Mais séria ainda é a possibilidade que temos de docilmente aceitar que o que vemos e ouvimos é o que na verdade é, verdade distorcida" (FREIRE, 2007, p.126).

Nesse critério o autor faz um alerta do quanto a realidade deixa míope o ser humano, e cuja preocupação com a natureza humana fica desproclamada pela falta de interesse humano. Argumenta ainda que, diante da realidade em que se encontra, deve emergir do ser humano o desejo, a intenção e a vontade de mudar, pois "[...] nenhuma teoria de transformação política social do mundo me comove 
sequer, se não parte de uma compreensão do homem e mulher enquanto seres fazedores da História e por ela feitos, seres da decisão, da ruptura, da opção" (FREIRE, 2007, p.129).

Sobre a educação ideológica, até os dias de atuais a instituição escola é reconhecida pela sociedade como um lócus para a transmissão do conhecimento acumulado, necessário para a formação do indivíduo como pessoa de relações. Cabe à escola decidir a direção e a finalidade desta formação. Recai sobre a educação a incumbência da formação de professores, que são alinhados teoricamente e politicamente com propostas pedagógicas que podem ser inovadoras elibertadoras ou conservadoras e ideológicas. Em outras palavras, pode ser o suporte para a consciência libertadora e transformadora ou alienante e massificadora.

Sob esse ponto de vista, os autores Bauman (2001) e Nóvoa (1991) salientam que propostas pedagógicas que teimam em permanecer na antiga solidez precisam perceber que estão formando para um paradigma que não existe mais. A modernidade líquida desafia propostas voltadas para a formação de um ser humano diferente, capaz de lidar com as intempéries desta época, sem perder a noção do todo como pessoa e como profissional. A educação, para este modelo de sociedade, deverá rever o seu projeto político pedagógico, que define com clareza e maestria a concepção de mundo e de ser humano desejada, pois nada do que se adquire é definitivo para o resto da vida. O ser humano é a personificação da dinâmica da vida, precisa estar em permanente processo de educar-se.

Feuerstein (2014) defende que os seres humanos precisam se autoperceber, pois são possuidores de uma identidade contínua. Esta abordagem otimista vem de uma visão flexível, cuja probabilidade de mudança é elevada. Isso leva a uma enorme diferenciação em tudo o que diz respeito à definição de objetivos e escolhas dos meios para alcançá-los na educação, no trabalho ou na vida pessoal.

Numa visão bastante esperançosa e otimista, Freire (2007) mostra a influência da educação sobre o comportamento. Para contrapor a influência ideológica, ele elegeu critérios para o exercício de uma prática que exige, além da formação, a disposição para aplicá-la. É uma adequação consciente, intencional e de caráter educativo. Cada um dos critérios é mobilizado nos diferentes contextos que envolvem educador e educando. Pode-se dizer que a autonomia pode ser considerada conceito-chave na sua obra. Esse termo pode ser utilizado como o empoderamento do indivíduo e se faz fazer presente nas suas necessidades e reinvindicações. 
Freire (2007) propõe um jeito diferente de ensinar e aprender referenciado em três capítulos: Não há docência sem discência; Ensinar não é transferir conhecimento; e Ensinar é uma especificidade humana. Aborda a influência de cada uma das condutas do educador no ato de ensinar e reforça o dever e compromisso ao afirmar que "[...] a importância do papel do educador, o mérito da paz com que viva a certeza de que faz parte de sua tarefa docente não apenas ensinar os conteúdos mas também ensinar a pensar certo".

A partir desse conjunto de elementos constitutivos do fazer pedagógico, conforme destacou o autor, nada é novo, são ações cotidianas, são posturas incorporadas ao fazer, que se estendem a outras relações em que homens e mulheres estão expostos todos os dias à experiência existencial.

No olhar de Feuerstein (2014, p.94), para

[...] os seres humanos agirem com competência, cumprir desafios, lidar com situações novas, devem sentir que são competentes para controlar estas situações, para vencer dificuldades, se familiarizarem com o novo e o desconhecido, e abordar desafios com a expectativa de que estes sejam vencidos.

Como se percebe, são posturas que evidenciam os atributos e as características para uma mudança de comportamento, que coincidem com diferentes formas de aprender e ensinar. Os ambientes de aprendizagem devem potencializar oportunidades de o educando aprender a desenvolver uma atitude de aprender sempre. Feuerstein (2013) considera uma atitude otimista, pois representa uma resposta que parte do indivíduo para o problema, é um progresso individual, que advém do esforço que surge de outras possibilidades de ensinar e aprender.

\section{APRENDER E ENSINAR SOB A ÓTICA DA TEORIA DA MODIFICABILIDADE COGNITIVA ESTRUTURAL E DAS IDEIAS DE FREIRE}

Os pensamentos pedagógicos de Feuerstein e Freire possuem caráter emancipatório, pois fortalecem a presença do educador e do educando no processo de aprendizagem. É uma relação que carrega princípios dialéticos que se constituem em elementos essenciais para o desenvolvimento de uma diferente proposta pedagógica. Ambos inspiram, sem dúvida, ações favoráveis à construção de diferentes modelos, pautados no diálogo, na intencionalidade 
e na reciprocidade. Ao defender uma concepção de educação alicerçada numa pedagogia da autonomia, Feuerstein e Freire ajudam a instaurar uma diferente relação entre educador e educando, determinada por uma também diferente intenção. Isso pressupõe um repensar, tomar iniciativas livremente, que demandam outros comportamentos, modos de pensar criativos e de agir coerentes com uma proposta que traga contribuições didáticas e que sustente o aprendizado no contexto complexo da sociedade contemporânea.

Aformaçãonecessária paraatenderaessascondiçõesimplicariaoqueFeuerstein (2014, p.10) defende como princípio pedagógico do autodesenvolvimento: uma dupla ontologia - a biológica e a social.

Esta modificabilidade não se refere à mudança de um comportamento específico, mas às mudanças de natureza estrutural que alteram o curso do desenvolvimento cognitivo, a forma em que o organismo interage, atua ou responde às fontes de informação. $O$ que o indivíduo experimenta é uma modificação cognitiva estrutural, que ocorre por meio de um programa de intervenção intencional e o torna mais sensível às fontes internas e externas de estimulação.

Feuerstein (2014) dedicou um capítulo do seu livro "Além da Inteligência" para reafirmar e testemunhar a capacidade de mudança no sistema neural. Sua intenção é clarificar ao leitor que existem muitas diferenças entre alunos com relação à habilidade de usar e adaptar o conhecimento a novas situações. Ele retratou o que significa a natureza estrutural da mudança e quais características fazem com que seja estrutural. Ele qualificou a mudança estrutural como sendo responsável por provocar transformações e afetar o aprendizado e o comportamento de forma profunda, sustentável e autoperpetuável.

A partir da sua constatação, apontou quatro aspectos importantes para se identificar a qualidade com que o aprendiz apresenta a mudança estrutural nos aspectos relacionados à: permanência, resistência, flexibilidade/adaptabilidade e generalização/transformação.

A permanência está empenhada em demonstrar até que ponto a mudança é preservada com o tempo, ou por meio dela se pode observar quais habilidades o aprendiz externa em reter e aplicar o seu conhecimento em outros contextos de aprendizagens.

A resistência diz respeito à mudança de condições das alterações ambientais, por exemplo, a mudança estrutural se confirma se o aprendiz não demonstrar instabilidade ao responder uma pergunta num nível mais complexo. A flexibilidade 
da mudança é uma variante oposta à resistência, pois requer do aprendiz a aplicação do comportamento adquirido em condições que diferem daquelas verificadas. Generalização/transformação, este grau de mudança é reconhecido como o mais alto nível de mudança estrutural. Neste nível o aprendiz consegue criar alterações estruturais por si mesmo, consegue se orientar no campo abstrato e extrair soluções ou princípios e regras que poderão ser aplicados a outros e diferentes situações problemas.

Sob este mesmo enfoque, lembra Freire (2007, p. 77) em relação à égide da mudança na:

[...] objetividade com que dialeticamente me relaciono, meu papel no mundo não é só o de quem constata o que ocorre mas também o de quem intervém como sujeitos de ocorrências. Constatando nos tornamos capazes de intervir na realidade, tarefa incomparavelmente mais complexa e geradora de novos saberes do que simplesmente de nos adaptar a ela.

De acordo com essa ideia, a modificabilidade cognitiva estrutural é definida como uma força que direciona o organismo para semodificar emodificar a estrutura do pensamento (FEUERSTEIN, 2014). Neste ponto de vista, a modificabilidade pode representar outra proposta a ser disseminada e trabalhada no contexto educacional, contribuindo assim com uma prática pedagógica emancipatória, libertadora e reflexiva na perspectiva do ensino e aprendizagem, como deseja Freire. Como tornar isso realidade? Começa-se pelo esforço pela implantação de políticas educacionais que contemplem formação de professores e investimento em pesquisa nesta direção. Está-se ciente de que esta deve constituir-se numa luta permanente de professores, pais, gestores e alunos que acreditam no potencial da educação no Brasil.

Deste pensamento crítico decorrem novas possibilidades para uma prática pedagógica calçada numa concepção de mundo, de ser humano e de sociedade desejada. A proposta pedagógica que surge a partir das mudanças vivenciadas pelo professor e aluno irá implicar mudanças significativas no processo de ensino e aprendizagem. Nesse aspecto, as manifestações na prática pedagógica serão reelaboradas nos processos do planejamento, da metodologia e da avaliação,

[...] com relação a aprender, é um processo que pode deflagrar no aprendiz uma curiosidade crescente, que pode torná-lo mais e mais criador. O que quero dizer é o seguinte: quanto mais criticamente se exerça a capacidade de aprender tanto mais se constrói e desenvolve que venho chamando "curiosidade epistemológica", sem o qual não alcançamos o conhecimento cabal do objeto (FREIRE, 2007, p.25). 
Ao se discutir o planejamento, trazem-se para reflexão conceitos e concepções como a de Gandin (1994). Ele propõe que se pense no planejamento como prática educativa, sempre estabelecendo um relacionamento entre a intencionalidade do professor e o seu trabalho na sala de aula. O planejamento tem objetivo de pensar estrategicamente propostas de trabalho, orientar e organizar ações de médio e longo prazo. Planejar é crer na possibilidade de intervenção na realidade. Por não ser neutro, o planejamento carrega um cunho político, pois se concretiza no contexto educacional como um compromisso político do educador, uma vez que ele toma decisões, faz opções, decide estratégias, isto é, opta diante de teorias pedagógicas e correntes epistemológicas.

Gandin (1994) reforça que não basta discutir o que seja o planejamento, é necessário o fazer crítico, pois este se traduz num requisito para a construção de um projeto identitário, construtor de novos fazeres pedagógicos. Tal articulação entre diferentes fazeres e a aceitação de outra postura se consolidam a construção de um plano de ensino focado não apenas em conteúdo, mas focado no ensino de habilidades do pensamento com ênfase em um tipo de raciocínio especializado. Gomes (2007, p.146) intensifica a relação do planejamento com o conteúdo, uma vez que "[...] o reconhecimento das relações entre as habilidades gerais metacognitivas, as habilidades modulares e as habilidades ontológicas de cada conteúdo é um aspecto importante a ser considerado".

A modificabilidade pressupõe provocar no aluno o próprio gerenciamento da sua aprendizagem. O processo de pensamento se estende para atividades de percepção e observação, construção estratégica para soluções de problemas. Todos esses aspectos contemplados no planejamento da aula desenvolverão processos metacognitivos importantes que impulsionarão a aprendizagem. É um processo que requer incentivo por parte do professor no momento de acompanhar seus alunos. Deve ser uma prática aperfeiçoada no planejamento, na qual o professor cria um clima de diálogo e troca experiências, tornando esta prática um hábito. Esta predisposição de aplicação e contextualização dos conteúdos deve se tornar um hábito no próprio estudante sobre o seu processo de aprendizagem.

A modificabilidade como condição para a aprendizagem requer efeitos de intervenção na estrutura cognitiva também pelo caminho da avaliação. Esta é considerada por Feuerstein (2013) como a intervenção para sondar se 
ocorreu aprendizagem significativa e qual o nível de mudança que ocorreu. Ao acompanhar a transferência da aprendizagem, torna-se importante o professor diagnosticar em quais situações as habilidades cognitivas estiveram em ação e quais foram generalizadas.

No entanto, uma avaliação planejada para provocar mudanças de alterações estruturais exige instrumentos de avaliação bem elaborados, que deixem claro o objetivo e o nível do conhecimento pretendido. Em outras palavras, exige a seleção e a condução metodológica apropriada. As atividades devem ser claramente pensadas e selecionadas em função do estágio em que se está e aonde se quer chegar. A interação em sala de aula deve ser um ponto pensado e organizado pelo professor, quanto maior a intencionalidade e a reciprocidade em sala de aula, maior será o resultado positivo da avaliação.

\section{CONSIDERAÇÕES FINAIS}

A educação escolar, na perspectiva da modificabilidade cognitiva, assume papel central na formação e na difusão de um sistema de aprendizagem capaz de fornecer as bases para a formação de indivíduos autônomos, críticos e capazes de se situar no mundo, os quais são sustentados em novos modos de ver e agir, de fazer escolhas, observar e intervir.

À medida que se vai amadurecendo no processo, vai-se ampliando cada vez mais a capacidade de aprender e ensinar. É uma construção que envolve atitude existencial proativa e constante perante a vida, na busca por diferentes saberes e no despertar do desejo de aprender sempre. As teorias de Feuerstein e Freire são contundentes sobre esse ponto de vista.

Esses dois educadores viveram as grandes mudanças do século XX e todas as conquistas e contradições dessas mudanças. A crença na capacidade que os seres humanos têm para aprender e o respeito pela busca de identidade que caracteriza toda pessoa são os aspectos que mais os aproximam, o que os torna tão universais (SOUZA; DEPRESBITERIS; MACHADO, 2004, p. 161).

Ao abordar este tema, espera-se ter gerado algumas reflexões sobre a possibilidade de diferentes formas de aprender e ensinar que podem ter sua gênese a partir da modificabilidade cognitiva estrutural e caminham pari passu ao que Freire desejava para o processo educativo com a intensão de enriquecer a prática educativa com aprendizagens significativas. 
Estende-se, assim, a necessidade de dar uma diferente dinâmica ao processo de ensino e aprendizagem para que se mude a sua essência "bancária" e vertical. Na perspectiva de Feuerstein e Freire, reformas educacionais significam alterações conjunturais, que se apresentam com maior capacidade em provocar mudanças mais profundas, com reflexos em outros segmentos da sociedade.

\section{REFERÊNCIAS}

BAUMAN Z. Modernidade líquida. São Paulo: Zahar, 2001.

CEPAL/UNESCO. Educación y conocimiento: eje de la transformación productiva con equidad. Santiago de Chile, agosto de 1992.

FEUERSTEIN R, FEUERSTEIN RS, FALIK LH, RAND Y. Il programa di arricchimento strumentale di Feuerstein. Trento: Erickson, 2013.

FEUERSTEIN R, FEUERSTEIN RS, FALIK LH. Além da inteligência Aprendizagem mediada e a capacidade de mudança do cérebro. Petrópolis: Vozes, 2014.

FREIRE P. Pedagogia da autonomia: saberes necessários à prática educativa. São Paulo: Paz e Terra, 2007.

GANDIN D. A prática do planejamento participativo. Petrópolis: Vozes, 1994.

GOMES CMA. Apostando no desenvolvimento da inteligência: em busca de um novo currículo educacional para o desenvolvimento do pensamento humano. Rio de Janeiro: Lamparina, 2007.

LÈVY P. A inteligência coletiva: por uma antropologia do ciberespaço. 3. ed. São Paulo: Loyola, 2000.

Ministério da Educação e Cultura (BR). Parecer CNE/CP n. 9/2001. Trata das diretrizes para Formação de Professores da Educação Básica, em nível superior, curso de licenciatura, de graduação plena. Disponível em: < http://portal.mec.gov.br/cne/ arquivos/pdf/009.pdf>. Acesso em: 15 jan. 2015.

Ministério da Educação e Cultura (BR).. Lei n. 9394 de 20 de dezembro de 1996. Altera a lei n.5692 de 05 de agosto de 1971 e estabelece as diretrizes e bases da educação nacional e dá outras providências. Diário Oficial [da] República Federativa do Brasil, Brasília, DF, 21 de dezembro de 1996.

NÓVOA A. Profissão Professor. Porto/ Portugal: Cidade do Porto, 1991.

SOUZA AMM, DEPRESBITERIS L, MACHADO OTM. A mediação como princípio educacional: bases teóricas de abordagem de Reuven Feuerstein. São Paulo: Senac, 2004. 
Artigo recebido em: 24/02/2015 Aprovado em: 03/09/2015

\section{Endereço para correspondência:}

Arnaldo Nogaro. Rua Assis Brasil, 709, prédio 08, sala 109, Frederico Westphalen, RS, CEP: 98400-000.E-mail: narnaldo@uri.com.br

Roque Strieder. Rua Assis Brasil, 709, prédio 08, sala 109, Frederico Westphalen, RS, CEP: 98400-000.E-mail: roque.strieder@unoesc.edu.br

Rute Rosângela Dalmina. Rua Assis Brasil, 709, prédio 08, sala 109, Frederico Westphalen, RS, CEP: 98400-000.E-mail: dalminaru@hotmail.com 